\title{
Inhibiting acid and Helicobacter pylori?
}

In 1995, Verdu et al published in Gut the interesting finding that the 24 hour intragastric $\mathrm{pH}$ during omeprazole therapy was about 5.5 in Helicobacter pylori infected volunteers compared with about 3.5 in uninfected controls, whereas the intragastric $\mathrm{pH}$ was similar in these groups without treatment. ${ }^{1}$ Later in 1995 they reported in Gut that this effect of $H$ pylori disappears six weeks after its eradication (their reference 2). In 1996 a further paper in the Scandinavian fournal of Gastroenterology showed that this correction is not transient but persists one year after eradication. ${ }^{2}$ Later in 1996 a paper in Gastroenterology from the same group showed that the same effect occurs in patients with duodenal ulcer disease (their reference 1). Interestingly, in relation to the present report, they noted that during treatment with omeprazole $20 \mathrm{mg}$ at 0915 hours, $H$ pylori infection had more effect on night time $\mathrm{pH}$ (6.4 in infected $v 2.1$ in uninfected subjects) than on overall 24 hour $\mathrm{pH}(5.5 v 3.0$ respectively). The study by Labenz et al in this issue asked whether $H$ pylori infection similarly increases the effect of the histamine $\mathrm{H}_{2}$-receptor antagonist ranitidine (see page 33). Eighteen patients with duodenal ulcer were studied during administration of ranitidine $300 \mathrm{mg}$ at night before and after eradication of $H$ pylori. Night time $\mathrm{pH}$ was again significantly higher in infected subjects $(6.8 v 5.4$ in uninfected subjects) but daytime $\mathrm{pH}$ was not affected. The authors point out that this difference can be explained by the lower potency and shorter duration of action of ranitidine compared with omeprazole. In short, therefore, these papers show that $H$ pylori infection exaggerates the effect of acid suppressing drugs on intragastric $\mathrm{pH}$, and this occurs whether acid is suppressed using either the proton pump inhibitor omeprazole or the $\mathrm{H}_{2}$-receptor antagonist ranitidine.

The authors discuss some of the putative mechanisms which might be responsible for this effect. Several products of $H$ pylori are known to inhibit secretion of acid by parietal cells. These include a protein described by Cave and Vargas, ${ }^{3}$ some unusual fatty acids produced by this bacterium ${ }^{4}$ and the vacuolating toxin. ${ }^{5}$ In addition, parietal cells can be inhibited by factors released in $H$ pylori gastritis. These include the cytokines tumour necrosis factor- $\alpha$ and interleukin-1 $\beta$ (their reference 19) and inhibitory autoantibodies directed against the proton pump itself. ${ }^{6}$ In an abstract, the authors provide data to support the idea that ammonia generated by the $H$ pylori enzyme urease causes the effects simply by neutralising gastric acid (their reference 10). Of course, the effect might be owing to a hitherto unrecognised factor and in this context it is important to note that intragastric $\mathrm{pH}$ is not only determined by parietal cell function. For example, the effect could be explained by changes in motility. $H$ pylori apparently increases the rate of emptying of gastric acid into the duodenum, which might be expected to raise the intragastric $\mathrm{pH}^{7}$ Increased duodenogastric reflux in $H$ pylor infection could also contribute. ${ }^{8}$
Whatever the mechanism, the results of this series of studies bear on the important and unresolved question of whether acid suppression alters the natural history of $H$ pylori gastritis. According to one view, the finding that acid suppression exaggerates the acid lowering effects of $H$ pylori supports other evidence that such treatment exacerbates $H$ pylori gastritis in the acid secreting corpus of the stomach. The authors cite the reports that proton pump inhibitors increase the number of bacteria and the degree of gastritis in this region (their references 5 and 6). In addition a report by Kuipers et $a l^{9}$ suggested that prolonged treatment with proton pump inhibitors exacerbates the tendency of $H$ pylori to promote gastric atrophy. However, this area remains contentious and more well designed studies are needed. The authors propose an alternative mechanism. $H$ pylori might increase parietal cell activity by producing $\mathrm{N}^{\alpha}$-methylhistamine (their reference 15), increasing gastrin and decreasing somatostatin concentrations, thus increasing the conversion of omeprazole to the active sulphinamide which depends on a low $\mathrm{pH}$ in the parietal cell canaliculus. However, this seems incompatible with their finding that intraluminal $\mathrm{pH}$ is raised. Finally, it should be borne in mind that the interaction could simply reflect the fact that $\mathrm{pH}$ is an inverse $\log _{10}$ scale, which means that minor changes in proton concentration have a much greater effect on $\mathrm{pH}$ at higher $\mathrm{pH}$. The number of protons required to change the $\mathrm{pH}$ by 1 point decreases by a tenth every time the $\mathrm{pH}$ is increased by 1 point.

The effect that the authors report may prove to be clinically important. The effect of $H$ pylori on the response to acid suppressing agents goes some way to explain variations in the response of different patients to these agents. A greater effect of acid suppressants in infected subjects may improve their contribution to $H$ pylori eradication regimens. Conversely, a fall in gastric $\mathrm{pH}$ following eradication of $H$ pylori might contribute to the frequent persistence of dyspeptic symptoms, such as acid reflux, the appearance of oesophagitis, ${ }^{10}$ and the frequent failure of those with non-ulcer dyspepsia to improve after eradication therapy. The finding also bears on the question of whether to eradicate $H$ pylori, if it is present, before beginning long term acid suppression in patients with oesophagitis. This was recommended at a recent consensus meeting in Maastricht. Undoubtedly, the stomach will be histologically healthier if this is done, although there is currently no evidence that this will be of clinical benefit to the patient. However, by increasing the effect of acid suppressing therapy, persisting $H$ pylori infection might lead to a healthier oesophagus and lower doses of medication. More research please!

ZOE HEALEY JOHN CALAM Department of Gastroenterology, Royal Postgraduate Medical School, Hammersmith Hospital, London W12 ONN 
1 Verdu EF, Armstrong D, Fraser R, et al. Effect of Helicobacter pylori status on intragastric $\mathrm{pH}$ during treatment with omeprazole. Gut 1995; 36: 539-43.

2 Verdu EF, Fraser R, Armstrong D, Blum AL. Effects of omeprazole and lansoprazole on 24-hour intragastric $\mathrm{pH}$ in Helicobacter pylori-positive volunteers. Scand f Gastroenterol 1994; 29: 1065-9.

3 Cave DR, Vargas M. Effect of a Campylobacter pylori protein on acid secretion by parietal cells. Lancet 1989 ; ii: $187-9$.

4 Beil W, Birkholz C, Wagner S, Sewing KF. Interaction of Helicobacter pylori and its fatty acids with parietal cells and gastric $\mathrm{H}+/ \mathrm{K}+$ ATPase. pylori and its fatty acids
Gut $1994 ; 35: 1176-80$.

5 Kobayashi H, Kamiya S, Suzuki T, et al. The effect of Helicobacter pylori on gastric acid secretion by isolated parietal cells from a guinea pig. Association with production of vacuolating toxin by $\mathrm{H}$. pylori. Scand $\mathcal{F}$ Gastroenterol 1996; 31: 428-33.
6 Negrini R, Lisato L, Zanella I, et al. Helicobacter pylori infection induces antibodies cross-reacting with human gastric mucosa. Gastroenterology 1991; 101: 437-45.

7 Hamlet A, Olbe L. The influence of Helicobacter pylori infection on postprandial duodenal acid load and duodenal bulb $\mathrm{pH}$ in humans. Gastroenterology 1996; 111: 391-400.

8 Ladas SD, Katsogridakis J, Malamou H, Giannopoulou H, Kesse Elia M, Raptis SA. Helicobacter pylori may induce bile reflux: link between $\mathbf{H}$ pylori and bile induced injury to gastric epithelium. Gut 1996; 38: 15-8.

9 Kuipers EJ, Lundell L, Klinkenberg Knol EC, et al. Atrophic gastritis and Helicobacter pylori infection in patients with reflux esophagitis treated with omeprazole or fundoplication. N Engl f Med 1996; 334: 1018-22.

10 Schutze K, Hentschel E, Dragosics B, Hirschl AM. Helicobacter pylori reinfection with identical organisms: transmission by the patients' spouses. Gut 1995; 36: 831-3. 